\title{
Study of the motility of the avian oviduct with chronically implanted electrodes
}

\author{
M. Roche and E. Brard \\ Laboratoire de Physiologie-Pharmacodynamie, Institut National des Sciences Appliquées de Lyon, \\ 20 avenue Albert Einstein, 69621 Villeurbanne Cédex, France
}

\begin{abstract}
Summary. Electrical activity was recorded in conscious hens from chronically implanted electrodes in the smooth muscle layers of the oviduct. Transport of the egg through the magnum resulted from an inhibition of the electrical activity in the oviduct cranial to the egg and an increased spiking activity caudally. During an ovulatory cycle the progression of the egg was related to four different patterns of the uterine motility: within a sequence, the ovulatory cycles varied according to the duration of Phases 3 and 4.
\end{abstract}

\section{Introduction}

The genital tract of birds greatly differs from that of mammals by (i) having a high metabolic rate linked to egg formation, (ii) being differentiated into the infundibulum which engulfs the ovum, the magnum which secretes ovalbumin, the isthmus which produces the shell membranes and the uterus, a pouch which retains the egg during the period of shell formation. Previous studies on oviductal motility have been related to the motility of isolated segments in vitro or to the measurement of intraluminal pressure in vivo (Crossley, Ayuy \& Ferrando, 1975). Talo \& Kekäläinen (1976) examined electrical activity of the hen oviduct in vitro, but electromyographic techniques have not been used for the genital tract in vivo, although electromyographic explorations of the digestive tract in conscious hens (Roche \& Decerprit, 1977) have shown that the birds are tolerant of the presence of chronic electrodes. Electromyographic study of the oviduct and uterus in mammals has shown that there are two basic components: bursts of spike potentials linked with the mechanical events and slow waves appearing with a decreased frequency from the ovarian end towards the cervix which are related to hormonal levels (Ruckebusch, 1975; Roche \& Brard, 1976; Ruckebusch \& Bueno, 1976).

The aim of the present work was to examine the correlations of the electrical activity of the oviduct in conscious hens with the egg movements.

\section{Materials and Methods}

The experiments were performed on 25 mature 10-12-month-old Leghorn hens housed individually in cages which allowed free movement but ensured sufficient restraint for long-term recording techniques. Food and water were always available and the lighting $(12 \mathrm{~h} \mathrm{light} / 24 \mathrm{~h})$ and temperature $\left(23^{\circ} \mathrm{C}\right)$ were constant. The electrodes were made from insulated Nichrome wires $(100 \mu \mathrm{m}$ diameter and $200-300 \mathrm{~cm}$ long); $0 \cdot 8 \mathrm{~mm}$ of the insulation was burnt from one end. After being fasted for $24 \mathrm{~h}$ the hens were anaesthetized with sodium pentobarbitone $\left(10 \mathrm{mg} \mathrm{kg}^{-1}\right)$ and after laparotomy on the left side each tripartite electrode was inserted, across the serosa, into the muscular layers by using a needle as a trocar; each part of the electrode was fixed $1.5 \mathrm{~mm}$ apart (Ruckebusch, 1970). The free end was tied off close to the wall and the electrodes were passed to the exterior between the wings. The tripartite electrodes were positioned on the antimesenteric side of the magnum at 2,8 and $30 \mathrm{~cm}$ from the infundibulum (Electrodes 1, 2 and 3), on the isthmus (Electrode 4) and on the mesenteric and antimesenteric sides of the uterus at 2 and $4 \mathrm{~cm}$ from the isthmus (Electrodes 5 and 6).

Recordings of the activity of the genital tract were obtained continuously for 2 months starting 20 days after surgical intervention. The electrodes were connected to a direct writing Polygraph (Reega 
XVI, Alvar; RC coupling; time constant $0.1 \mathrm{sec}$, paper speed $2.5 \mathrm{~mm} / \mathrm{sec}$ ). In addition, the polygraph was connected via a linear integrator of the spiking activity at $20 \mathrm{sec}$ intervals (Latour, 1973) to a potentiometric recorder (Philips PM 8222; paper speed $2 \mathrm{~cm} / \mathrm{h}$ ). Cineradiographic equipment (Siemens) allowed observation of the egg movements along the genital tract.

\section{Results}

\section{Patterns of electrical activity}

Two types of electrical activity were closely related to the passage of the egg along the magnum. Caudal to the developing egg the magnum exhibited a constant activity of isolated potentials $(800 \mu v)$ firing at a regular rate (4-6/min). Cranial to the egg the spiking activity was increased: regular small $(80 \mu \mathrm{v})$ bursts of $4-8$ spike potentials continuously propagating towards the uterus were intermingled with strong bursts of $30-50$ spike potentials, the amplitude and rate $(3-5 / \mathrm{min})$ of which were progressively decreasing by $2-3 \mathrm{~h}$ after egg passage (Text-fig. 1). There was no such activity with antiperistaltic propagation.

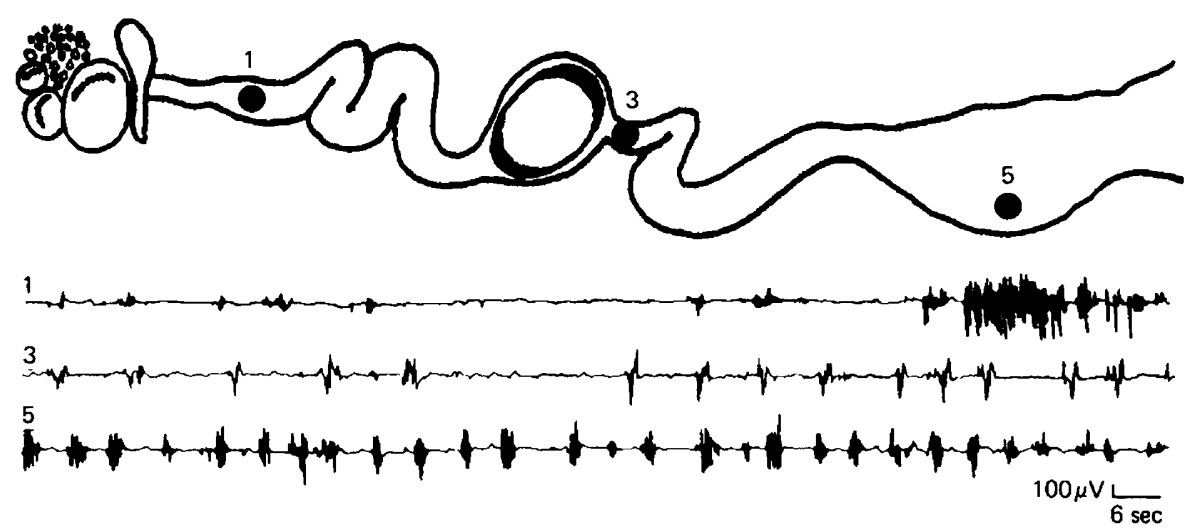

Text-fig. 1. Changes in the electrical activity of the hen oviduct according to the position of the egg. There are sporadic spike potentials on the magnum in front of (Electrode 3) and after (Electrode 1) passage of the egg. High amplitude activity occurs in the uterus (Electrode 5).

Only small $(50 \mu \mathrm{v})$ isolated spike potentials were recorded on the isthmus and uterus before the onset of laying cycles. Two main types of spike potentials were distinguished during the natural laying cycle: strong bursts of potentials $(0 \cdot 8-2 / \mathrm{min})$ starting near the magnum and continuous smaller bursts of potentials caudally propagated $(9-12 / \mathrm{min})$ increased until oviposition. Rotary movements of the egg occurring during the period of shell formation were observed and were accompanied by bursts of spike potentials localized at the different regions of the muscular layers of the uterus. All the bursts were simultaneously propagated caudally a few hours before oviposition.

\section{Uterine spiking activity, egg movements and sequential laying}

The laying pattern of the hens occurred in sequences of 4 eggs, each sequence being separated from the next by one pause day which was characterized by a decreased uterine motility (Text-fig. 2 ). The duration of each ovulatory cycle exceeded $24 \mathrm{~h}$ and eggs were laid later and later after the onset of the light period. 
During ovulation the oviduct electrical activity was inhibited for 40-90 min (Text-figs 2 and 3) (Phase 1). The movements of the developing egg into the magnum were accompanied by a constant slow motility of the uterus (Phase 2); after entry into the isthmus there was a progressive increase in the motility (Phase 3). A marked increase occurred 2-6 h before oviposition (Phase 4) which was followed by contractions. of all the muscular layers. The abrupt decrease of the lumen diameter after egg laying was related to uterine monophasic waves of high amplitude $(0 \cdot 9-1 \cdot 2 \mathrm{mV})$ firing at a rate of $20-25 / \mathrm{min}$ during $20-30 \mathrm{~min}$.

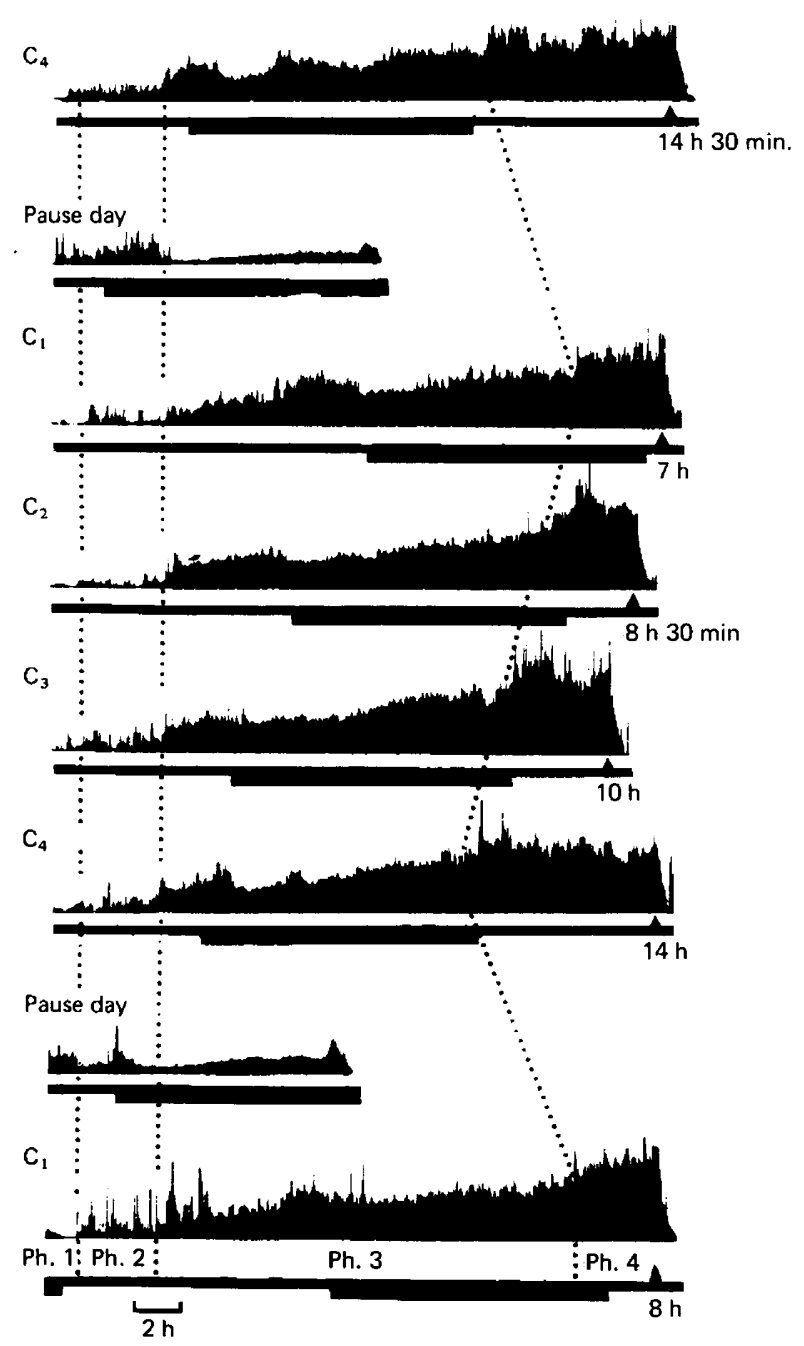

Text-fig. 2. Changes in the pattern of uterine electrical activity in the hen during a sequence of laying. The integration of spike potentials during a sequence of four eggs $\left(C_{1}-C_{4}\right)$ shows a decrease in the length of each ovulatory cycle from $C_{1}$ to $C_{3}$ because of the shortening of Phase 3 , and an abrupt increase in the last cycle $\left(C_{4}\right)$ because of the lengthening of Phase 4 . The sequences are separated by a pause day. The time of oviposition is indicated by the arrows on the right-hand side, and the dark period is shown by the thickened horizontal bar.

The duration of Phases 1 and 2 was constant and not correlated with the position of the oviposition cycle in the sequence, while Phase 3 was shortened from the first to the last ovipository cycle. The duration of Phase 4 was constant for cycles $Z_{1}$ to $C_{3}$ and increased suddenly in the last ovi- 
pository cycle $\mathrm{C}_{4}$ (Text-fig. 2). The variations of the two last periods of the uterine motility during an oviposition cycle induced a progressive reduction in the duration of the whole ovipository cycle from $C_{1}$ to $C_{3}$, but reduction of Phase 3 in the $C_{4}$ cycle was compensated for by a longer Phase 4 .

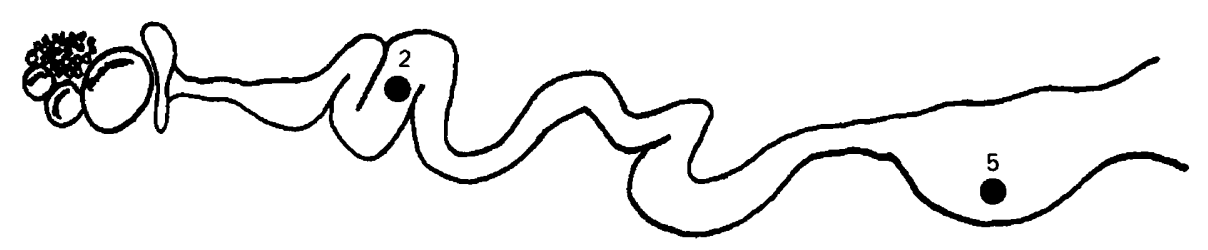

(a)

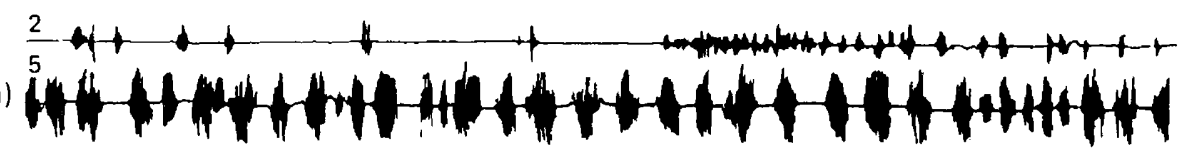

(b)

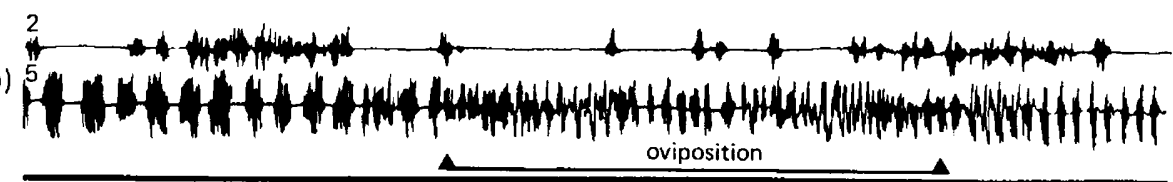

oviposition

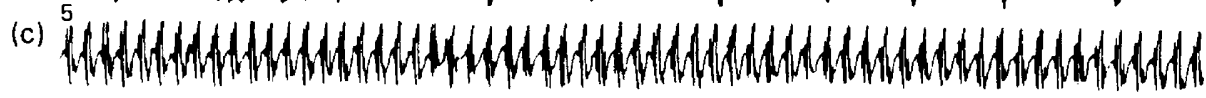
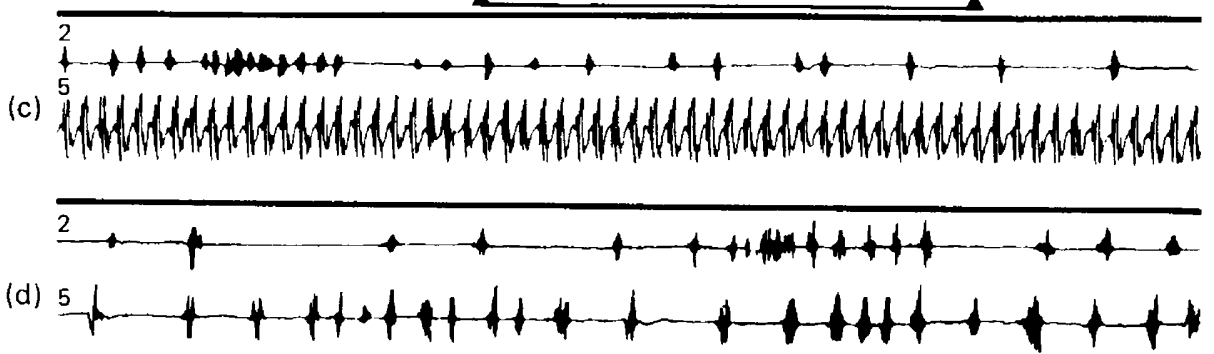

(e)

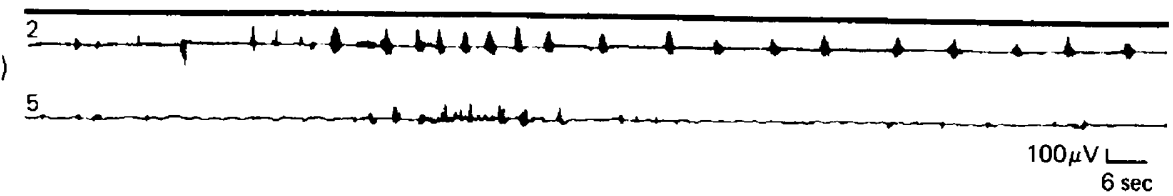

Text-fig. 3. Electrical activity of the magnum (Electrode 2) and the uterus (Electrode 5) of the hen (a) $90 \mathrm{~min}$ before the oviposition; (b) during oviposition; and (c) $10 \mathrm{~min}$, (d) $20 \mathrm{~min}$, and (e) $1 \mathrm{~h}$ after oviposition. Oviposition (b) is immediately preceded by high-amplitude spike bursts (a), followed by monophasic slow waves (c) and progressive decrease of the electrical spiking activity ( $d$ and $e$ ).

\section{Discussion}

A general view of the changes of spiking phases of the hen oviduct clearly indicates a relationship between uterine motility, egg transport and sequential laying organization. Our data indicate that the frequencies and amplitudes of electrical activity are greater in the uterus than in the isthmus and magnum. Transport of the egg results from an inhibition of activity of the smooth muscle caudal to the egg. An electrical activity of high amplitude cranial to the egg allows progression of the egg through the magnum, without antiperistaltic movements. These results, like the observations made by Talo \& Kekäläinen (1976), suggest some similarity with the gradual decrease of pressure from the cranial to the caudal end of the mammalian intestine which results from the slow propagation 
of a phase of regular spiking activity, as mentioned by Bueno, Fioramonti \& Ruckebusch (1975). In the hen the spiking activity of the uterus is only propagated towards the vagina during a few hours before oviposition, but contrary to the observations of Crossley et al. (1975) our results indicate that antiperistaltic propagation of the electrical activity is exceptional. This apparent discrepancy may be due to the different techniques used: laparotomy and mechanical stimulation of the intraluminal recording balloon may interfere with the physiological motor events.

Laying hens kept in a photoperiod of $12 \mathrm{~h}$ daylight $/ 24 \mathrm{~h}$ show a circadian mechanism, with an egg transport time of about $24 \mathrm{~h}$ (Fraps, 1954). Our results show that the intervals between ovulatory cycles decreases slowly from the 1st to the last but one cycle and abruptly increase for the last cycle. These changes are related to Phases 3 and 4 of uterine activity. The abrupt increase of Phase 4 during the last ovulatory cycle requires further studies, including those of the hormonal changes involved.

We are grateful to Dr Yves Ruckebusch for his helpful suggestions and guidance in writing this manuscript.

\section{References}

Bueno, L., Fioramonti, J. \& Ruckebusch, Y. (1975) Rate of flow of digesta and electrical activity of the small intestine in dogs and sheep. J. Physiol., Lond. 249, 69-85.

Crossley, J., Ayuy, A. \& Ferrando, G. (1975) Some physiological characteristics of motility in the in vivo avian oviduct. Biol. Reprod. 13, 495-498.

FRAPS, R.M. (1964) Neural basis of diurnal periodicity in release of ovulation inducing hormone in fowl. Proc. natn. Acad. Sci. U.S.A. 40, 348-356.

LAtouR, A. (1973) Un dispositif simple d'analyse quantitative de l'électromyogramme intestinal chronique. Annls Rech. Vétér. 4, 347-353.

Roche, M. \& BRARD, E. (1976) Motricité du tractus génital femelle (T.G.F.) chez les Mammifères. Corrélations hormonales. C.r. Séanc. Soc. Biol. 170, 129-135.
Roche, M. \& DECERPRIT, J. (1977) Controles hormonal et nerveux de la motricité du tractus digestif de la Poule. Annls Rech. Vétér. 8, 25-40.

Ruckebusch, Y. (1970) The electrical activity of the digestive tract of the sheep as an indication of the mechanical events in various regions. J. Physiol., Lond. 210, 857-882.

Ruckebusch, Y. (1975) Relationship between the electrical activity of the oviduct and uterus of the rabbit in vivo. J. Reprod. Fert. 45, 73-82.

RuCKebusCh, Y. \& Bueno, L. (1976) An electromyographic study of uterotubal activity in the ewe. $J$. Reprod. Fert. 47, 221-227.

TALO, A. \& KEKÄLÄINEN, R. (1976) Ovum promotes its own transport in the oviduct of the Japanese quail. Biol. Reprod. 14, 186-189.

Received 26 July 1977 